\title{
ABDOMINAL PREGNANCY \\ An attempt to determine the Incidence of Implantation of Fertilized Ova in the Peritoneal Cavity, with notes on a personal case
}

\author{
By T. A. QuilliaM, M.B., B.S., M.R.C.S. \\ Lately Assistant Resident Surgeon, St. Charles' Hospital, London
}

In a recent communication, Nicolson (1947) reported a case in which a fertilized ovum became secondarily implanted in the pouch of Douglas and he observed that the condition is comparatively rare. It is a matter of considerable difficulty to ascertain the frequency with which this condition occurs as the following review shows.

Robinson (I948) has reviewed some early cases whilst Sittner, in a series of articles published between 1901 and 1908 , found 200 cases of abdominal pregnancy of 22 or more weeks' gestation in the literature of the preceding century. , Hellman and Simon (1935) incorporated Sittner's work when reviewing the more recent literature and by adding five personal cases they were able to gather together details of 316 cases. Those occurring after 1906 were included only if the gestation period was 28 weeks or more. Cornell and Lash (I933) collected 226 cases of proven abdominal pregnancy published during the previous 20 years and added ten personal cases to this list, but made no distinction as to the length of the gestation period.

More recently, Mason (1940) found 66 cases in the English literature from 1933 to 1939 , and added a further three cases. Mattingly and Menville (1942) collected 42 cases of abdominal pregnancy from the literature of the previous six years. Between July, 1945, and June, 1946, details of 1 I abdominal pregnancies were found in the world literature.

Wynne (1919), when discussing the 303 ectopic pregnancies admitted to the Johns Hopkins Hospital between 1890 and I9I6, pointed out that these constituted 1.3 per cent. of total gynaecological admissions. He failed, however, to indicate the frequency of abdominal pregnancies in his series. Falk and Rosenbloom (1936) in an analysis of $3 \mathrm{I} 3$ cases of ectopic pregnancy occurring in the Harlem Hospital between March, I917, and February, 1934, calculated that these cases constituted 3.49 per cent. of all the gynaecological admissions requiring surgical treatment. (For the last ten years of their survey the frequency was about 2:5 per cent.) During this 17 year period four abdominal pregnancies were noted. Mayo and Straussman (1938) found only one case of true abdominal pregnancy in their series of $\mathrm{I}_{42}$ ectopic pregnancies occurring between 1926 and 1935. Siegler (1945) collected a series of 127 ectopic pregnancies (of which one was classified as abdominal) from the records of the Unity Hospital over a period of 15 years. Ectopic gestations constituted 2.3 per cent. of the gynaecological admissions and ectopic gestations occurred at the rate of 8.2 per 1,000 deliveries. Lee (1946), in a five year study at the Swedish Hospital, Seattle, lists 58 ectopic gestations (one of which was abdominal). During the same period deliveries and abortions totalled 10,000 approximately. Macfarlane and Sparling (i946), surveying the Gynaecological Service of Montreal over a ten year period, found 1 IO cases of ectopic pregnancy, three of which were classified as ' probably abdominal.' Cases of ectopic gestations constituted 1.26 per cent. of gynaecological admissions requiring surgical intervention.

Over a 20 year period starting in 1928,83 ectopic pregnancies have been operated upon in St. Charles' Hospital. (Only one of these was abdominal.) They constituted 2.8 per cent. of the total gynaecological operations (194I-1947) and 0.4 per cent. of all surgical operations (1928-1947).

It is interesting to note that figures derived from St. Leonards' Hospital in the East End of London show that during the period 1937-1947, 16 ectopic gestations were operated upon. They represented 2.3 per cent. of the gynaecological admissions requiring surgical treatment and 0.2 per cent. of cases of all kinds operated upon. No case of abdominal pregnancy was recorded. During a typical ten-year period (1926-1935) 73 cases of ectopic pregnancy were operated upon in St. Thomas's, a London teaching hospital. They constituted $\mathrm{r} .4$ per cent. of gynaecological operations, 0.12 per cent. of total operations and 0.66 per cent. of pregnancies admitted. No case of abdominal pregnancy occurred, but a survey of a further ten years revealed that one abdominal pregnancy had been described, an incidence for 
TABLE $\mathbf{r}$

An Estimate of the Annual Incidence of Abdominal Pregnancy

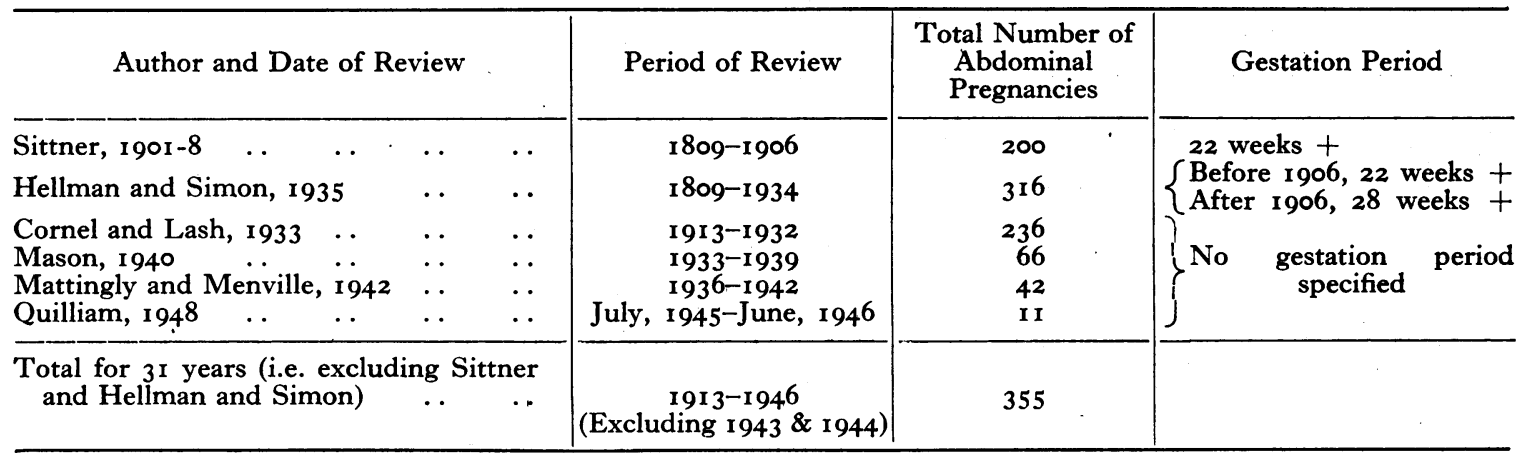

ConCLusion:-Average annual incidence of abdominal pregnancy is approximately i $\mathrm{I}$ cases.

TABLE 2

The Incidence of Abdominal Pregnancy

\begin{tabular}{|c|c|c|c|c|c|c|}
\hline $\begin{array}{c}\text { Author and Date of } \\
\text { Review }\end{array}$ & $\begin{array}{l}\text { Period of } \\
\text { Review }\end{array}$ & $\begin{array}{l}\text { Number of } \\
\text { Gynaeco- } \\
\text { logical } \\
\text { Admissions }\end{array}$ & $\begin{array}{l}\text { Number of } \\
\text { Ectopic } \\
\text { Gestations }\end{array}$ & $\begin{array}{c}\text { Number of } \\
\text { Abdominal } \\
\text { Implanta- } \\
\text { tions }\end{array}$ & $\begin{array}{c}\text { Percentage of } \\
\text { Ectopic } \\
\text { Gestations } \\
\text { Implanted } \\
\text { in the } \\
\text { Abdomen }\end{array}$ & \begin{tabular}{|c|} 
Percentage of \\
Gynaecological \\
Admissions \\
Formed by \\
Ectopic \\
Gestations
\end{tabular} \\
\hline Wynne, r9ig. & $1890-1916$ & 22,688 & 303 & - & - & $\mathbf{I} \cdot 3$ \\
\hline 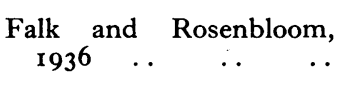 & $1917-1934$ & 9,060 & 313 & 4 & I .28 & $\begin{array}{c}3 \cdot 5 \\
(2.5,1925-1936)\end{array}$ \\
\hline $\begin{array}{llr}\text { Siegler, r945 } & \ldots & . . \\
\text { Lee, r946 } & . & . \\
\text { Macfarlane and } & \text { Sparling, }\end{array}$ & $\begin{array}{l}\text { I930-1 } 945 \\
\text { I } 940-\text { I } 945\end{array}$ & $\underline{5,568}$ & $\begin{array}{r}127 \\
58\end{array}$ & $\begin{array}{l}\mathbf{I} \\
\mathbf{I}\end{array}$ & $\begin{array}{l}0.8 \\
1.7\end{array}$ & $2 \cdot 3$ \\
\hline $\begin{array}{cccc}\text { 1946 } & . & . & \\
\text { Quilliam, } & \text { 1948 } & . . & .\end{array}$ & $\begin{array}{l}1934-1944 \\
1941-1947 \\
(1928-1947)\end{array}$ & $\begin{array}{l}8,705 \\
1,360\end{array}$ & $\begin{aligned} \text { I } 10 \\
39 \\
(83)\end{aligned}$ & $\begin{array}{c}3 \text { (prob.) } \\
\text { I } \\
(\mathrm{I})\end{array}$ & $\frac{2 \cdot 7}{(1 \cdot 2)}$ & $\begin{array}{l}1.26 \\
2.8 \\
-\end{array}$ \\
\hline $\begin{array}{l}\text { Totals : } \\
\text { (r) Excluding Wynne.. } \\
\text { (2) Also excluding Lee } \\
\text { and Quilliam }\end{array}$ & - & $\begin{array}{c}- \\
\text { (a) } 24,693 \\
\text { (b) } 24,693\end{array}$ & $\begin{array}{l}691 \\
589 \\
\end{array}$ & $\begin{array}{l}10 \\
-9\end{array}$ & $\begin{array}{r}1 \cdot 45 \\
- \\
-\end{array}$ & - \\
\hline
\end{tabular}

Conclusions :-

I. $1.45 \%$ of all ecotopic pregnancies are implanted in the abdomen.

2. $2.4 \%$ of gynaecological admissions are formed by ectopic pregnancies.

3. I case of abdominal pregnancy occurs in every 2,750 gynaecological admissions.

that condition of about I per cent. of all cases of ectopic pregnancy admitted during the 20-year period. (Bowes and Harrison, personal communication.)

Bodenheimer (1940) reported the occurrence of three abdominal pregnancies occurring in coloured women among 10,000 deliveries during the previous four years at the Shreveport Charity Hospital, whilst in the Charity Hospital of Louisiana, New Orleans, 25,000 deliveries took place during a five-year period in which ro abdominal pregnancies were recorded, all in coloured women. (Mattingly and Menville, 1942.) In Lee's series only one abdominal pregnancy occurred during the same period as 10,000 deliveries and in Siegler's series one abdominal pregnancy occurred during the 
TABLE 3

The Relation of Abdominal Pregnancy to the Total Number of Pregnancies Admitted to Hospital

\begin{tabular}{|c|c|c|c|c|c|}
\hline Institution unde & Review & Period of Review & $\begin{array}{l}\text { Total Number of } \\
\text { Pregnancies }\end{array}$ & $\begin{array}{c}\text { Number of Ectopic } \\
\text { Gestations }\end{array}$ & $\begin{array}{c}\text { Number of Abdominal } \\
\text { Pregnancies }\end{array}$ \\
\hline $\begin{array}{l}\text { Charity Hospitals } \\
\text { Swedish Hospital } \\
\text { Unity Hospital }\end{array}$ & $\begin{array}{l}. \\
\cdots \\
\ldots\end{array}$ & $\begin{array}{r}9 \text { Years } \\
5 \text { Years } \\
\text { I } 5 \text { Years }\end{array}$ & $\begin{array}{l}35,000 \\
10,000 \\
14,966\end{array}$ & $\begin{array}{r}\overline{58} \\
127\end{array}$ & $\begin{array}{r}13 \\
\mathbf{I} \\
\mathbf{I}\end{array}$ \\
\hline \multicolumn{2}{|c|}{$\begin{array}{l}\text { Total (excluding Charity Hos- } \\
\text { pitals) }\end{array}$} & & 24,966 & 185 & 2 \\
\hline
\end{tabular}

Conclusions :-

I. For every 135 pregnancies seen in hospital one ectopic pregnancy is operated upon ; and

2. For every 12,500 pregnancies (approximately) hospitalized, one abdominal pregnancy is recorded.

same period as 13,542 deliveries and $I, 424$ abortions. The high frequency of abdominal pregnancy recorded in the Charity Hospitals may thus be related to racial factors. These series have therefore been excluded from the estimate of frequency of occurrence made in Table 3 .

Much of the data referred to above has been summarized in tabular form below.

From the data given above, it is possible to draw the following conclusions :-

I. About I I cases of abdominal pregnancy have been reported annually in the literature of the past $3 \mathrm{I}$ years.

2. Ectopic gestations of all types constitute 2.4 per cent. of all gynaecological admissions requiring surgical intervention.

3. I.45 per cent. of all types of ectopic gestation are found to be abdominal pregnancies, which thus constitute about one in every 2,750 gynaecological admissions which require surgical treatment.

4. Approximately one abdominal pregnancy occurs in every 12,500 pregnancies of all types seen in hospital practice.

5. One ectopic gestation occurs in every $\mathrm{I} 35$ cases of pregnancy admitted to hospital.

\section{A Case of Intra-Peritoneal Pregnancy probably occurring by Secondary Implantation}

Brief case history :

Mrs. G., aged twenty-nine, married, with four children, was admitted to St. Charles' Hospital as a case of 'septic abortion' on November 2 Ist, 1945. She had been an in-patient there one year previously with aspirin poisoning.

She stated that her L.M.P. was on August 24th, 1945, and that her pregnancy had proceeded normally until November 9th, 1945, when she took six 'Ladies Occasional Pills' (' normal' dosagetwo tablets). She had had a two-hours red loss P.V. shortly afterwards. She had noticed during
November 2oth and 2ist abdominal pain (" like i labour pains ') and she had had a heavy loss P.V. i She had vomited once and complained of pain on $\mathrm{G}$ micturition. Bowel action was normal.

On examination

T., 99.2 ${ }^{\circ}$ P., 120. R., 20. Urine, N.A.D.

The patient was pale and had a moist coated tongue.

Heart, lungs and C.N.S., normal.

Abdomen, tenderness present all over, most marked in the tubal areas.

P.V., all fornicies very tender. The uterus w\& not easily felt but the cervix was badly torn and movement of it was restricted and caused pai She had a slight red loss.

\section{Treatment}

Non-operative treatment was instituted and the patient was put on a course of sulphadiazine. Progress during the next few days was good and on November 28 th, 1945, she had only a very slight loss P.V., and only occasional 'niggling' pain. On December 3 rd, 1945, she had no loss or pain and was allowed up to the toilet. On December

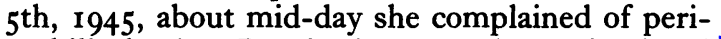
umbilical pain. Respirations were 'grunting 'and rapid. The abdomen was distended and tender all over. She vomited once. Vaginal examination revealed a bulky, mobile uterus. The posterior fornix was 'boggy.' The right fornix was hard but not tender. In the left fornix a tender fallopian tube was felt. A putrid discharge developed P.V.

Immediate laparatomy was decided upon.

A right paramedian incision was made. The peritoneal cavity contained much blood and a large placenta-like mass was located in the upper part of the pouch of Douglas. This was found to be attached to the sigmoid colon from which it was manually separated, leaving a raw oozing area which was packed with hot swabs. Some oozing persisted, in spite of all efforts to check it and so 
on closing the abdomen a rubber drain was inserted into the pouch of Douglas. Apart from some enlargement of the body of the uterus no abnormality was detected in the pelvic genital organs.

A foetus estimated to be of two-and-a-half to three months' gestation, surrounded by chorionic membrane, was found in the specimen removed at operation.

Post-operatively, two pints of blood were given. The drainage tube was removed after 48 hours, during the first 24 of which, discharge of blood was considerable.

The patient was discharged from hospital on December 24th, 1945, after an uneventful recovery.

\section{Summary}

In a review of all available British and American literature, it has been possible to estimate that ectopic gestations of all types constitute 2.4 per cent. of all gynaecological admissions to hospital requiring surgical intervention. Of these ectopic gestations, 1.45 per cent. are abdominal pregnancies which thus constitute about one in every $2,75^{\circ}$ gynaecological cases. Roughly one abdominal pregnancy occurs in every 12,500 pregnancies of all types seen in hospital practice. One case of ectopic gestation occurs in every 135 cases of pregnancy hospitalized.

A case of abdominal pregnancy, secondarily implanted on the sigmoid colon, is described.

\section{BIBLIOGRAPHY}

BODENHEIMER, J. M. (1 940), Nєw Orleans Med. \& Surg. F., 92 , CORNELL, E. L., and LASH, A. F. (1933), Inter. Abst. Surg.,

FALK, H. C., and ROSENBLOOM, M. A. (1936), Surg. Gynec. छ' Obst., 62, 228.

HELLMAN, A. M., and SIMON, H. J. (1935), Am. F. Surg., 29,

LEE, A. F. (1946), Northwest. Med., 45, 40.

MACFARLANE, K. T., and SPARLING, D. W. (1946), Am. $\mathcal{F}$. Obst. E' Gynec., 5I, 343 .

MASON, L. W. (1940), Am. F. Obst. EO Gynec., 39, 756.

MATTINGLY, D., and MENVILLE, L. J. (I942), Radiol., 38, 35. MAYO, C., and STRAUSSMAN, E. O. (1938), Surg. Gynec. छొ Obst., $67,46$.

NICOLSON, E. L. (1947), Brit. Med. F., $2,998$.

ROBINSON, T. (1948), Proc. N. of E. Obst. E Gynec. Soc. (in

Sress). S. L. (1945), New York State Med. F., 45, 1974

SITTNER, A. (1901), Arch. f. Gynäk, 64, 526.

SITTNER, A. (1903), Zentrabl. f. Gynäk., 27, 33.

SITTNER, A. (1906), Deutch. Med. Wchnechr., 29, 743; 32, 1200. SITTNER, A. (1908), Die. Heilkunde, 12, 201.

WYNNE, H. M. N. (1919), Bull. Johns. Hop. Hosp, 30, 15.

\section{Angioneurotic Oedema}

' One of the most remarkable instances of fugitive inflammation affecting various parts of the body, which has come under my notice, occurred in the person of a gentleman lately under my care. I shall not go through the whole history of his disease, of which he has favoured me with a very minute account, but shall merely state that he is of a gouty habit, has had an attack of gout in the stomach, and is at present subject to a gouty affection of a very extraordinary character. After labouring for some time under languor and weakness, accompanied by spasms, pain and sense of weight in the stomach, the pain of the stomach ceases, and his face begins to swell at various points, generally commencing on the forehead, and involving the cheek and eye so as to close up the latter. He first feels as if a small current of air was directed on the face ; then, as it were the fillip of a finger, or the bite of a gnat ; and on looking in the glass, he suddenly perceives a tumour rising on the forehead, which in the space of half an hour, becomes as large as a pigeon's egg, and, as he expresses it, moves down until it closes the eye. Sometimes it attacks his lips, and other parts of his face, but never affects his nose. These tumours have also appeared on various parts of his body and he observes in his letter to me; that he is sometimes led to think that they attack his stomach also. Before and during an attack of the face, which generally occurs on the left side, the discharge from the nostril of the affected side ceases.

'But what is chiefly remarkable in this case is the singular character of the local affection. The tumours arise, run through the course, and disappear in the space of a few hours, and on the following day there is no trace of their existence. Sometimes the lips, inside of the mouth, palate and uvula are attacked, giving rise to a very considerable inconvenience. Were such tumours to occur in the neighbourhood of the glottis, I need not say that they would be pregnant with danger of no ordinary character. I may observe that this gentleman has derived great benefit from the use of hydriodate of potash, and from decoction of sarsaparilla with nitric acid, and that his health is at present much improved. His case presents a very curious example of transient local inflammation depending on the gouty diathesis.'

GRAVES, ROBERT J., 'Clinical Lectures on the Practice of Medicine,' Dublin, 1843 . 